\title{
Cloud based Housing Society Management System
}

\author{
Tirth Shah \\ Information Technology Department, \\ Sardar Vallabhbhai Patel Institute of Technology, Vasad \\ Gujarat Technological University
}

\begin{abstract}
This paper focuses on a platform through which user can manage the housing society by a web system which is cloud based and make current situations of society more simple and efficient. Nowadays there is a plethora of societies in every city. Society management system provide facilities like property tracker, online maintenance payment, notification system, expense tracking, annual report generation etc. By using this system members can connect with each other based on their interest group. Software is cloud based so that it can be modified easily as per the society's requirements. This system is able to support many users without any maintenance from the developer.
\end{abstract}

\section{Keywords}

Property Tracker, Online Maintenance Payment, Notification System, Web Oriented, Cloud Based.

\section{INTRODUCTION}

Usually, in housing societies all the maintenance related work is decided by the society meetings. If any person of society is not available for the meeting then he/she has no idea about the decisions which are taken in meeting. Housing societies uses a conventional method for storing a data and manages all the society related work.

There is a lots of wastage of papers in maintaining the database of society. This system provides a cloud based platform to housing societies on which they can manage all work related to the society. By using the platform, society committee can manage all the task very efficiently. The main goal of this project is to provide a property tracker system to the society, through which society members and users from the outside of the society can also get information about houses which are available for sell/rent.

\section{EXISTING SYSTEM}

Housing societies works on conventional method, they do all their work manually. Progress of the compliant is very slow. Necessary steps take time to apply on complaints. Also the members of their own society are not aware about houses which are available for sell/rent. That's why needful person never get it. By using conventional method society member miss their maintenance payments date and then they have to pay the penalty. This system provides a notification system using that no one will miss the due date of payment of maintenance. Also system provides a property details, by using which everyone can get information about the property status.

ApartmentAdda app uses two different applications for the users and admin. This is total intransparency between society committee and residents and sometimes it become very tough to handle two different application simultaneously. This system remove this barrier. It will make a crystalline relationship between society committee and residential.

\section{PROPOSED SYSTEM}

This system is fully automated, cloud based and most important it is user friendly. System provide various features in the system. i.e. Online maintenance payment, property tracker, notification system (remainders for due dates of various payments), online voting system for different positions of society like secretary, Chairman and treasurer etc. System also provide database of the whole society, so that if anyone wants to communicate with any person in their society they can easily get contact number of them. i.e. in midnight if any resident has medical emergency then they just need to search on the system by profession of doctor, if there is any doctor who lives in society then system shows the result. Ease of communication is the aim of the system.

Nowadays softwares are created which are cloud based. User can easily modified cloud based software. Hardware failures do not result in data loss because of networked backups. Cloud computing uses remote resources, saving organizations the cost of servers and other equipment.

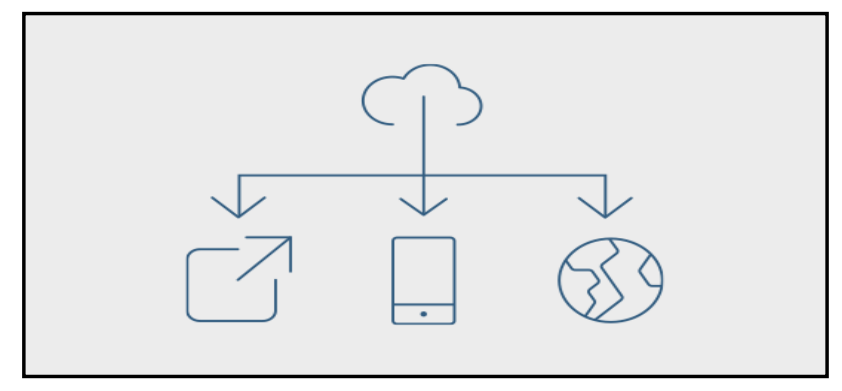

Figure 1. Diagram for cloud computing

Users can scale services to fit their needs, customize applications and access cloud services from anywhere with an internet connection.

Storage Options: Users can choose public, private or hybrid storage offerings, depending on security needs and other considerations.

Security Features: Virtual Private cloud, encryption and API keys help keep data secure.

The following are the features and functions which are presented in proposed system: 


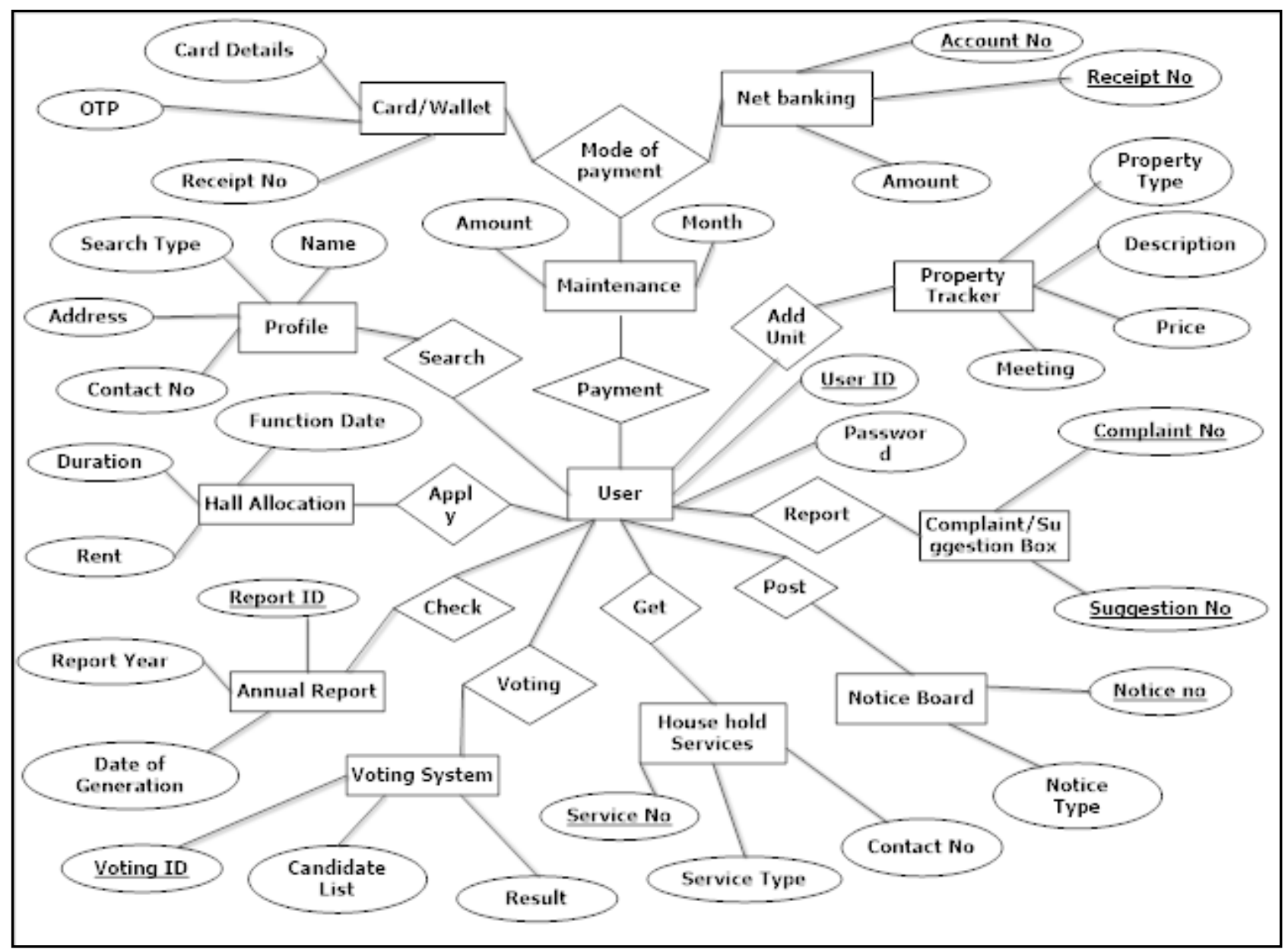

Figure 2. Diagram for system

\section{a. Property Tracker}

In housing co-operative societies to sell a house or to give it on rent this task becomes so headache for owner. So the system provides a platform on which owner of the house can register his/her house for sell/rent. For that owner need to give all the information about house and also upload the pictures of house. In case of selling, owner has to set a selling price. In case of rent, owner can gives the details about the condition (i.e. which kind of tenant can apply) and also display the rent per month.

If anyone is interested in that advertisement then the system provides a meeting feature too, through which they both (buyer and seller) can decide meeting time.

This function also provide one additional feature which is privacy display. In which user can set it in two options:

I. Advertisement can be access only by the resident of society.

II. Advertisement can be access by everyone. Someone who does not live in society can also access it by just visiting the website.

\section{b. Online Maintenance Payment}

Society members can pay their maintenance bill online using credit/debit card or through net banking. On successful transaction system will generate e-receipt of payment. Member can save it or they can take print of it.
While member pay their maintenance, system will also show their pending bills. So that member would come to know that how much amount they have to pay.

This must have security protocol and procedures in place to ensure transactions are more secure. This can also include having a certificate from an authorized certification authority (CA) who provides PKI (Public-Key infrastructure) for securing credit and debit card transactions.

\section{c. Complaint/Suggestion Box}

Member can report their complaints and suggestion using the system interface. Admin and secretary have authority to reply on complaints. User can track their complaint using system interface.

\section{d. Notice Board}

This is not the conventional type of notice board which used by existing system. This notification board has feature of notifying each and every member of society personally. It will use notification function of the system.

User can display important announcements, meeting schedules, gathering updates, event updates and most important thing which system provide to the society member is that they can do advertisement of their home businesses (if any). So that residents come to know about the business and they can utilize the services which are serve by that business. 


\section{e. Notification System}

This is the new feature which is not provide by any existing housing management system. Every society members will get notification for bill payments, announcements which are displayed on notice board.

\section{f. Household Services}

Information of vendors who provides various services like housekeeping, security, lawn moving, cleaning solar panels, making beds and general tidying, assistance with grocery shopping, wood chopping and stacking etc.

\section{g. Voting Management}

Provides the online voting for various positions of the society. Different posts will assigned to candidates and the whole voting system managed by administrator. The result of voting will be declared on home page of system interface.

\section{h. Annual Report Generation}

Record and track all the expenses of society, record of description of expenses, date of expense and total amount.

Upload list of expenses in an excel sheet format. Prepare an annual expense report. Based on expenses report make a society fund report.

\section{RESULTS}

Using this feature system want to keep transparency between society members and society committee.

\section{i. Hall Allocation}

This system will be used to allocate a hall or common plot for celebration. Only society secretary can allocate hall to society members. Before allocation hall secretary has to check whether hall is acquired by any other member or not. If it is not then he can do further proceeding.

\section{j. Login and Administration}

Add house owner individually by administrator. Add all the information about members of house and add personal information too. ( i.e. number family members, occupation, contact number etc.)

After successful addition, automated text message will be send to each member containing their personal user-id and password through which they can access the system and its services. Secretary has the special privileges of updating monthly bills.

\section{a. Property Tracker}

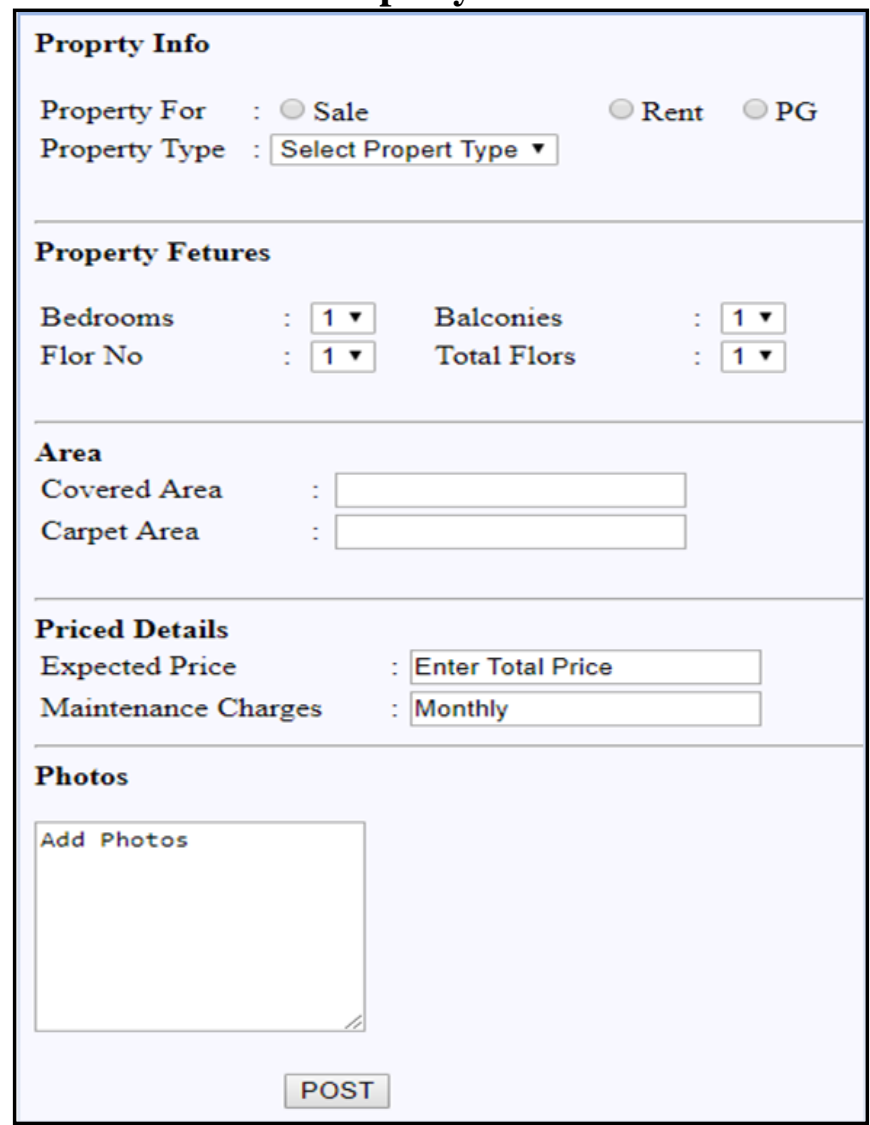

Figure 3. Interface for property tracker 


\section{b. Maintenance Payment}

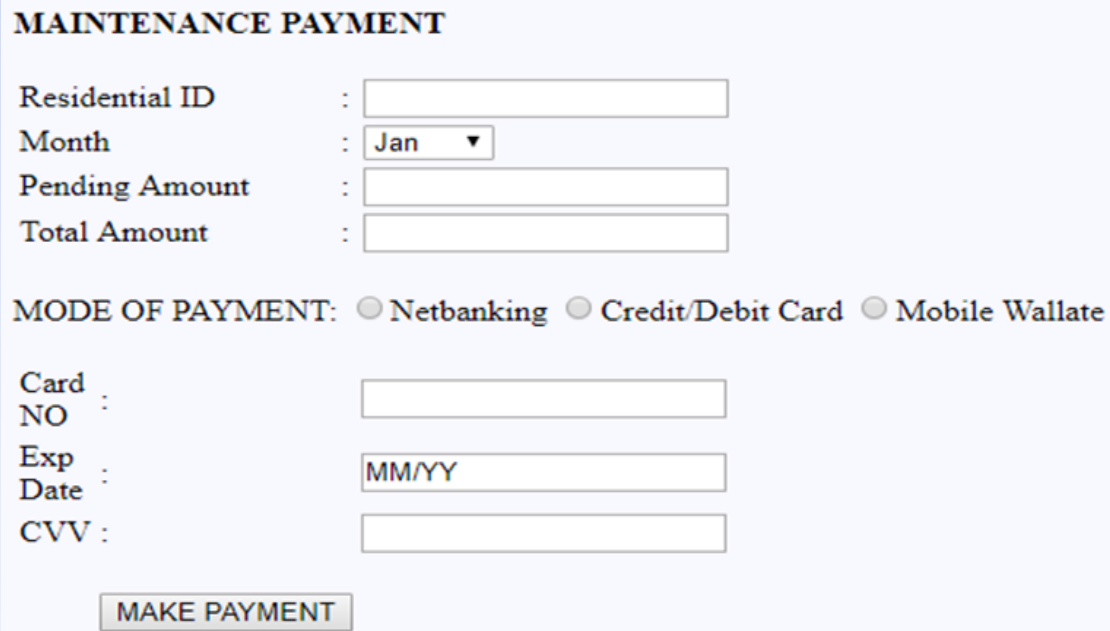

Figure 4. Interface for online maintenance payment

\section{c. Complaint Box}

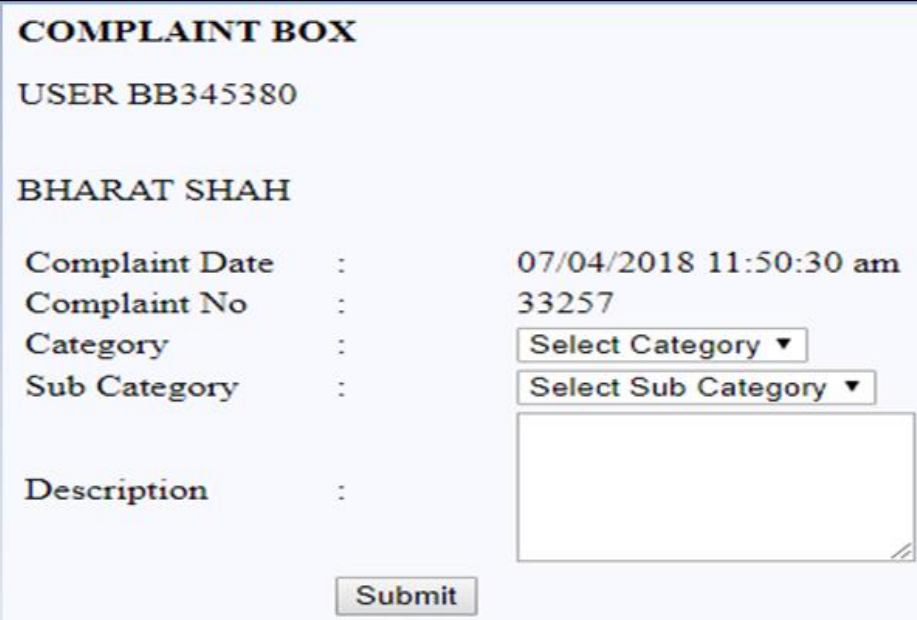

Figure 5. Interface for complaint box 
d. Annual Report Generation

ANNUAL REPORT
Year(2017)
\begin{tabular}{|l|l|l|}
\hline No. & PARTICULARS & AMOUNT \\
\hline 1. & 10th Year Celebration & 20,280 \\
\hline 2. & Watch-man Sallary & 36,000 \\
\hline 3. & Electricity charges & 98,856 \\
\hline 4. & Payments to Workes & 50235 \\
\hline 5. & Pooja Expenses & 30,376 \\
\hline 6. & Diwali Celebration & 20,560 \\
\hline & TOTAL: & $3,06,307$ \\
\hline Print & & \\
\hline
\end{tabular}

Figure 6. Interface for annual report generation

e. Hall Allocation

HALL BOOKING

Booking ID : 23451

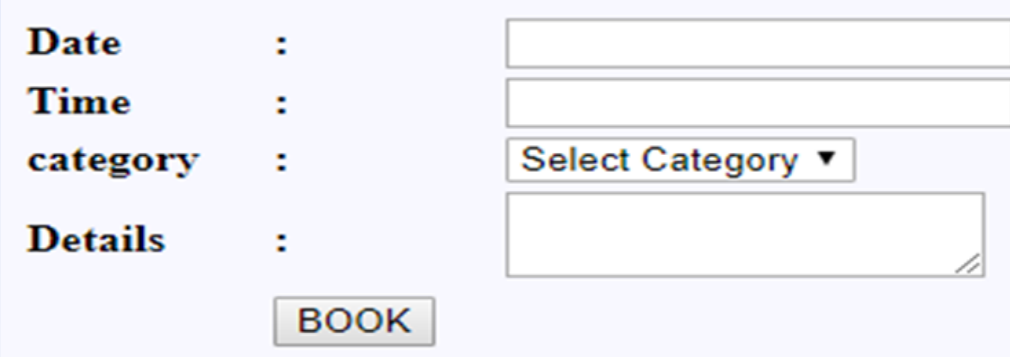

Figure 7. Interface for hall allocation 


\section{f. Registration}

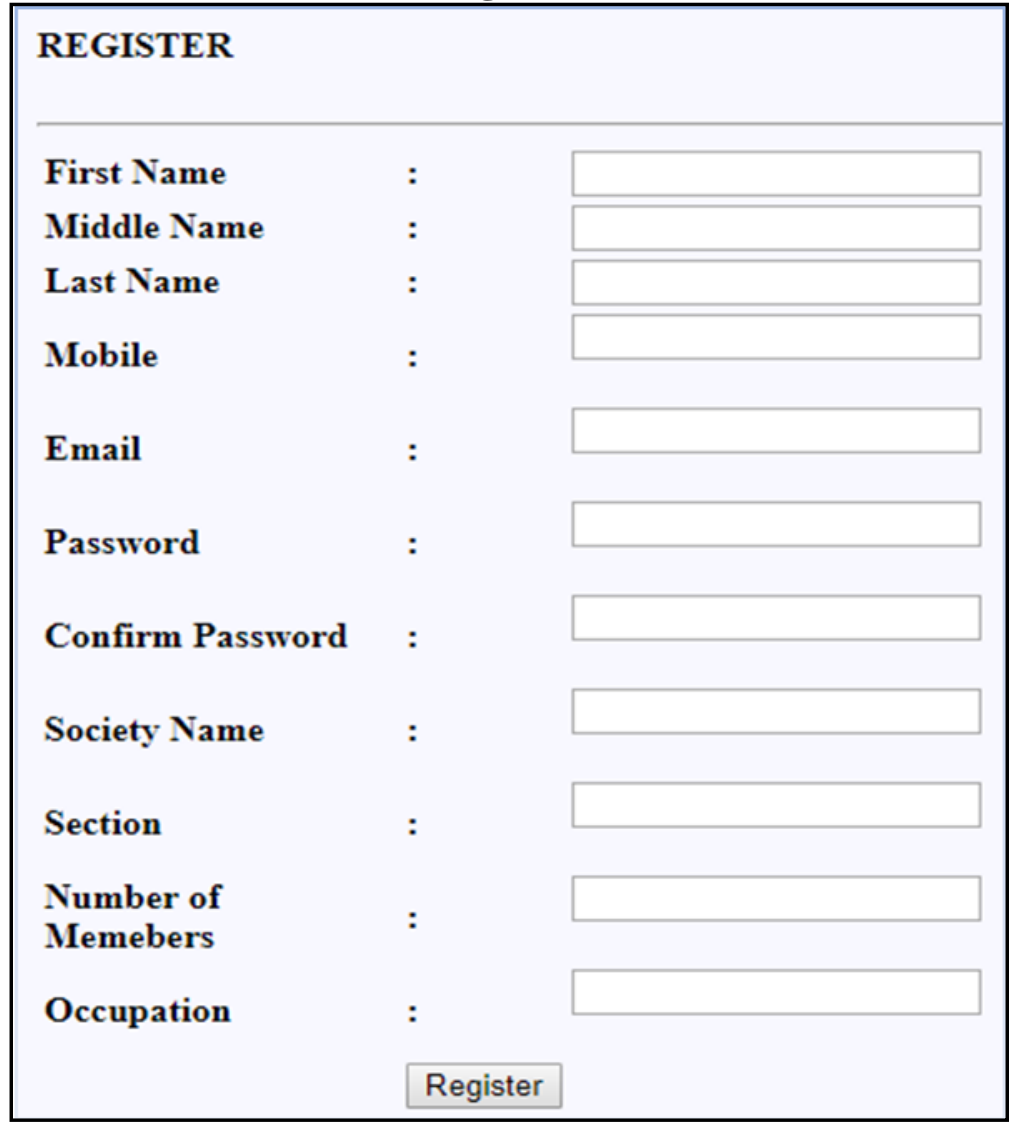

Figure 8. Interface for registration

g. Login

\section{Login \\ Society ID : \\ User ID \\ Password \\ : \\ $\operatorname{login}$ \\ don't have account? Contact}

Figure 9. Interface for login

\section{CONCLUSION}

The system helps house owner for sell or rent their houses. Also the system manage online maintenance payment for the society residents. There is no need to meet the society committee personally because every residents can check annual budget report and expense report online. Resident can report their complaints via this system and also they can track the progress of their compliant. System's best try to give a secure network to the residents that is why it uses cloud based technology with various security options. It is a less expensive solution for your society management works which will save your money and most importantly time.

\section{FUTURE SCOPE}

This project can be intensify further by developing a Mobile Application. Also it will become more secure using gateway technology which include three features (i) Data Masking Technology (ii) Secure Logic Migration and Execution Technology (iii) Data Traceability Technology. The software become more flexible enough to be modified and executed as per future needs. 


\section{REFERENCES}

[1] Cloud Computing: From Beginning to End by Ray J. Rafaels published April 2015

[2] Cloud Computing: Concepts, Technology \& Architecture by Thomas Erl Published May

[3] Database Design Using Entity-Relationship Diagrams by Sikha Bagui, Richard Earp

[4] Simple and Usable Web, Mobile, and Interaction Design By Giles Colborne
[5] Computer Aids to Hosuing Maintenance Management Paperback-1981 by Raymond Pettitt

[6] Housing Management Simplified by Adelora Dairo, published in 2014

[7] Electronic Payment Systems for E-commerce by Donal O'Mahony, Hitesh Tewari, and Michael A. Peirce

[8] http://www.society123.com/stpages/featurelist.html

[9] https://post.magicbricks.com

[10] https://www.societynmore.com 